regrtettably less readable than it might be. As part of the story of our civilization it suffers perhaps from too narrow an approach. The view of capitalism here presented is likely to prove but a passing phase in a long record of oppression and misery from which man is only now beginning to emerge. Some slight corrections are called for in the book on points of detail : thus, in dealing with the formative seventeenth century Mr. Dobb persistently pre-dates the Commonwealth, and his acquaintance with Clarendon's career seems slight. But these are minor blemishes in a work of this scope.

Dr. Gutkind presents in his "Revolution of Environment" what cannot be called more than a selection of occasional papers. The underlying theme is the interaction of society and environment and the need to plan environment for the improvement of society. Illustrations are taken from China, Russia and the Jesuit settlement in Paraguay, and there is a series of striking plates which unfortunately bear neither numbers nor any definite relation to the text. Much interesting material is presented; but such conclusions as are drawn offer little guidance through current difficulties. Thus a delightful picture of Great Britain "after it has passed through its Revolution of Environment" is presented on p. 94 , but it seems remote. Nevertheless, at a time when town and country planning are on the nation's agenda it is well that we should consider what we are aiming at, though perhaps Dr. Gutkind is over-zealous for "new men with new ideas striving towards new goals". New Presbyter may prove to be little more than Old Priest writ large.

MaURIOE BRUCe

\section{SCIENCE AND CRIME}

\section{Forensic Chemistry}

By Henry T. F. Rhodes. Second edition revised. Pp. vii + 164. (London : Chapman and Hall, Ltd., 1946.) 15s. net.

$\mathrm{T}$ $\mathrm{HE}$ structure of the second edition of this work is essentially that of the earlier edition. In Part 1 of the book the author discusses the evidential value of skin-prints, occupational dust, and the grouping of blood and semen in the identification of the individual. Part 2, dealing with the application of chemical methods to the proof of corpus delicti, covers such miscellaneous matters as stains, firearms and explosives, questioned documents, counterfeit money and toxic agents.

Certain sections, notably those on dusts and stains, and on toxic agents, have been very largely rewritten. Revision of the former sections has undoubtedly enhanced the usefulness of the book; but the inherent difficulty of treating so vast a subject as forensic chemistry in a volume of this size still reveals itself in a somewhat unbalanced product.

The author emphasizes in his preface that "the subject matter is strictly confined to formally chemical theory and technique". It is difficult to appreciate the insistence upon this rigid segregation of the science, and it appears to have been responsible for several serious omissions. In the short but lucid summary of blood grouping no reference is made, even in passing, to the absorption technique, while in the identification of blood stains, confirmation of the preliminary chemical tests by the precipitin reaction is entirely omitted.
The description of the utilization of micro-methods, and in particular of a micro-form of Stas-Otto procedure, in the examination of dust and debris is a commendable feature. Micro-methods are considered at length in several sections of the book, and some economy in space might well have been effected by the fairly safe assumption that those to whom forensic chemical investigations are entrusted are familiar with the general elementary technique of microanalysis. On the other hand, the spectrograph, that almost indispensable tool of the forensic chemist, is dismissed in three lines with the note that it "is not within the scope of this book", but that "in many cases it is very useful".

The chapter on questioned documents is by far the longest individual section in the book, and treats in an interesting and informative manner not only of the chemical examination of paper, inks and pencils, but also of such subsidiary materials as sealing-wax and adhesives. Sacrifice of the detailed discussion of the molecular structure of tannic acid and iron tannates would not detract from the quality of the chapter.

It is unfortunate that revision of the concluding chapter, on chemical toxicology, has not resulted in a more satisfactory treatment of the subject. Limitation of space inevitably precludes any detailed description of procedure (although arsenic is dealt with at inordinate length), but summaries of the basic processes for the separation of the main groups of poisons should certainly have been included.

The book, which is written throughout in the author's usual excellent literary style, is intended as a "practical guide for those engaged in forensic chemistry", and within its limited confines it provides a valuable introduction to many of the problems confronting the forensic analyst.

\section{G. E. TURFITT}

\section{ANIMAL BIOLOGY}

\section{Principles of Animal Biology}

By Prof. A. Franklin Shull, with the collaboration of Prof. George R. Larue and Alexander G. Ruthven. (McGraw-Hill Publications in the Zoological Sciences.) Sixth edition, second impression. Pp. xi +425. (New York and London: McGraw-Hill Book Co., Inc., 1946.) $20 s$.

7 HE necessity for a second impression of the sixth edition of this well-known text-book is sufficient evidence that it meets a widespread demand for a general elementary account of the principles of animal biology. It first appeared in 1920, and various changes have been introduced in successive editions; but those in the present edition are more than usually varied and affect the general plan. It may seem rather surprising to find one of the early chapters devoted to an account of some fundamental physics and chemistry, for apparently in the United States it is possible for a student to graduate in biology without any previous knowledge of those subjects. But in Britain there is a corresponding and probably more widespread ignorance among those graduating in chemistry or physics, who are frequently unacquainted with even the rudiments of any branch of biology.

'The first part of the book deals with the functions of protoplasm, cells, cell division (in which the names of 